\title{
Numerical Simulation of a Clear Air Turbulence (CAT) event over Northern India using WRF modelling system
}

\author{
Gitesh Wasson, Someshwar Das and S. K. Panda \\ Department of Atmospheric Science, School of Earth Sciences, Central University of \\ Rajasthan, Bandar Sindri, Kishangarh, Ajmer, Rajasthan, 305817, India
}

Corresponding author. E-mail: subrat.atmos@curaj.ac.in

\section{Abstract}

Atmospheric turbulence is a primary meteorological hazard to en-route air traffic. The role of Clear Air Turbulence (CAT) for various processes in the atmosphere is still ambiguous. An Air India flight AI462 encountered severe CAT on 19 April 2018. The present study simulates the CAT event and is focused on understanding and investigating favourable conditions for the occurrence of CAT. Weather Research and Forecasting (WRF) Model V4.0.3 has been used to simulate the turbulence. The 6-hourly NCEP FNL Operational Global Analysis data at $0.25^{\circ} \mathrm{X} 0.25^{\circ}$ resolution is taken as input to provide the model's initial and lateral boundary conditions. For simulating the atmospheric environments at the time of the event, Yonsei University Scheme, WSM 3-Class Simple Ice Scheme, KainFritsch (New-Eta) Scheme, Rapid Radiative Transfer Model (RRTM) Scheme, and Revised MM5 Monin-Obukhov Scheme are used. This study shows that Vertical Velocity, Geopotential Thickness, Wind Shear and Bulk Richardson Number Shear are correlated with CAT as the model predicted both upward and downward velocity very close to each other between $400 \mathrm{hPa}$ and $550 \mathrm{hPa}$ levels along with strong geopotential thickness gradient and strong wind shear gradient near the accident location. This could lead to CAT. Model simulated variations in CAT Index with change in time and pressure levels. CAT dissipates as we go higher in the atmosphere above $550 \mathrm{hPa}$.

Keywords: Clear Air Turbulence, vertical wind shear, CAT Index, Ellrod's Index, aviation meteorology, aircraft hazards.

\section{Introduction}

Turbulence is a primary meteorological hazard to en-route air traffic. At high altitudes, 30 aircraft may encounter turbulence unexpectedly without any significant cloudiness. Clear Air 
31 Turbulence (CAT) occurs when severe turbulence occurs in an environment with no clouds.

It creates a ferocious buffeting effect in aircraft. The role of CAT for various processes in the atmosphere and vice versa is still ambiguous. CAT occurs in a statically stable shear layer, typically found amid the high troposphere and low stratosphere. CAT is non-convective turbulence not within the Planetary Boundary Layer (PBL). CAT is "aircraft turbulence that occurs at $5.6 \mathrm{~km}$ or higher altitudes, either in cloud-free condition or within stratiform clouds" (Ellrod et al. 2003). According to the Meteorological College office (1997), CAT is horizontally $80-500 \mathrm{~km}$ along wind direction and $20-100 \mathrm{~km}$ in the across-wind direction having vertical dimensions 500-1000 m. "CAT exists in the atmosphere for about 30 minutes to 24 hrs" (Stefan et al. 2020).

"The physical impact of CAT on crew and passengers varies from discomfort to injuries, loss of flight control, and in some sporadic instances, fatalities have befallen. Repeated turbulence encounters that occur during the lifetime of an aircraft might advance to metal fatigue and, in sporadic cases, structural failure" (Ellrod et al. 2003). Commercial airlines have economic loss also due to meteorological hazards as there is a significant increase in fuel consumption during turbulent flights. So, knowing the unknown about CAT is important for Aviation Safety. Favourable conditions for the occurrence of violent turbulence or CAT, leading to low-level aircraft hazards, are passage of an active cold front; preceding the time of thunderstorm; mountainous terrain; arced parts of jet-stream which might be much more likely to contain turbulence than beeline jet-stream parts; convergence area of polar and subtropical jet-stream; and the presence of vertical wind shear, horizontal shear, convergence, deformation zone, strong thermal wind gradient, and steep lapse rate. From the actual first flight, pilots are acquainted with mid-flight turbulence. In the 1940s, a previously unidentified phenomenon was discovered as fighter aircraft reached the interface between the troposphere and the stratosphere. This phenomenon was termed Clear Air Turbulence (CAT) as antecedent encounters were experienced in cloudless regions. Throughout the latter half of the $20^{\text {th }}$ century, CAT attracted several organized research efforts because the aircraft was designed to fly at significant heights and speeds. As an outcome, our acquaintance with CAT has developed substantially. Between 1967-2010, "the relative contributions of meteorological phenomena to weather-related aircraft accidents shows that turbulence was associated with $66 \%$ of the cruise flight accidents and $56 \%$ of accidents occurred during descent whereas, CAT accounted for 13\% of accidents during cruise flights, and 7\% of accidents during descent" (Mazon et al. 2018). Studies concluded that "the frequency of CAT would increase significantly in the next 50 years due to 
strengthening of jet stream velocities" (Williams and Joshi 2013). "CAT is more frequent in the tropopause region" (Dutton and Panofsky 1970) near the jet stream as "jet stream contains about three times more CAT than the rest of the atmosphere" (Reiter 1963). About $60 \%$ of CAT incidents are associated with the jet stream.

Two widely accepted mechanisms supporting CAT formation are Kelvin Helmholtz Instability (KHI) and Mountain Waves. In most cases, KHI triggers CAT as it uses the mechanical energy from the vertical wind shear. Thus, forecasting CAT is challenging without understanding vertical shear (KHI). "Mountain waves are also a source of CAT. There have been several cases where severe CAT was encountered in areas with no significant KHI favourable conditions" (Hopkins 1977). Another CAT production mechanism is Internal Gravity Wave (IGW). The excitation of the IGW also affects the manifestation and strength of CAT from different sources and resonant non-linear relations amongst different IGW modes and among IGW and KHI in turbulent layers. "Low values of Richardson number (i.e., Ri < 1), discontinuity in lapse rate, significant cyclonic horizontal shear, and large vertical velocity $(\sim 1 \mathrm{~m} / \mathrm{s})$ are triggering factors for CAT" (Venkatesh et al. 2014).

Forecasting and predicting CAT is a challenge for Meteorologists, as it is generally a microscale phenomenon having a small temporal and spatial dimension, making it challenging to attain consistent and inclusive observations. In the early 1960s, a basic jetstream turbulence model was developed in United Airlines by their meteorology department. "Some advances in our knowledge of the global distribution of CAT along heavily traveled airways have been derived from programs to collect PIREPs, like one conducted by ICAO in the mid-1960s. A comprehensive global 'climatology' of large-scale and upper-level conditions favourable for CAT was created using a numerical model to determine the distribution of a globally averaged CAT index equal to the product of horizontal deformation and VWS" (Ellrod et al. 2003). In the United Kingdom in the late 1970s, "turbulence data from 4500 aircraft reports were compared with 11 co-located numerical parameters derived from a coarse-resolution prediction model. It revealed that the best correlation was between CAT and vertical and horizontal wind shears. Similar studies were completed in the United States in the 1980s using higher-resolution numerical model data that showed CAT to be highly correlated with horizontal deformation and scalar wind speed" (Ellrod et al. 2015). "Two models were introduced for CAT prediction, i.e., eddy and wave motions models" (Lester 1993). An ensemble model can be used to create a Global probabilistic turbulence forecast. Most of the indicators used now are derived from the deterministic model. "Using Met Office Global and Regional Ensemble Prediction System (MOGREPS), an ensemble 
forecast can predict turbulence by the probabilistic indicator of wind shear" (Gill and

100 Buchanan 2013). Today, no warning system can ascertain CAT at archetypal flight altitudes.

101 CAT is a severe security issue for aircraft as there are no land or onboard detection gadgets.

102 Even the onboard weather radars are unsighted to CAT. "Doppler LIDAR has been under

103 research and development for many years to measure wind velocities and CAT detection.

104 Research indicates that moderate CAT could be detected at ranges of 5-8 km and up to $100 \mathrm{~s}$ 105 ahead of an aircraft" (ICAO 2005). "WRF Model is also used widely for turbulence 106 prediction and studies related to CAT" (Passner 2008).

107 It is essential to have an objective and meaningful approach to verify and improve the forecasting of CAT. The aim of this study is mainly to understand the dynamic processes that can trigger CAT events; to simulate a turbulence event of 19 April 2018 using the WRF V4.0.3 Model; to correlate CAT parameters with the WRF Model derived parameters for the selected CAT simulation; and to understand the reliability of turbulence indices, TI1 and TI2,

112 for predicting CAT. Section 2 describes the data, methodology, and model study.

113 Experimental design has been described in section 2.4, whereas results and discussion are explained and analyzed in section 3.

\section{Methodology and Modelling Framework}

\subsection{Study Area}

117 There are two domains in the ratio $3: 1 \mathrm{~km}$ resolution, as shown in Fig. 1. Domain 1 (D01) 118 with $6 \mathrm{~km}$ horizontal resolution covers the flight route from Amritsar to Delhi that 119 encountered the CAT event. Nested domain 2 (D02) with $2 \mathrm{~km}$ horizontal resolution is 120 focused on Amritsar's vicinity where the flight encountered the CAT event. On 19 April 2018, 121 Air India flight AI462 took off at 0923 UTC from Amritsar. While passing from FL80 to 122 FL210, light to moderate turbulence unexpectedly grew severe. The aircraft encountered 123 severe turbulence unexpectedly while climbing out from Amritsar between FL160 and 124 FL190. Once in severe turbulence, while passing through FL180, auto-pilot disengaged at 1250929 UTC, and auto-thrust was also disengaged at 0930 UTC. Momentarily, the aircraft climbed almost 600 feet above the cleared level (DGCA Report 2019).

\subsection{Data}


resolution with 6-hourly intervals was used as initial and boundary conditions for the model integration for 48 hours from 0000 UTC of 18 April 2018 to 0000 UTC of 20 April 2018. Model is configured as $6 \mathrm{~km}$ for Parent Domain (D01) and $2 \mathrm{~km}$ for Child Domain (D02). ECMWF ERA-Interim (ECMWF 2011), IMDAA (Rani et al. 2021), and NGFS (Prasad et al. 2016) data sets were also used in this study to analyze the CAT event. The specifications of all the data utilized in this study are stated in Table 1.

\subsection{Methodology}

The WRF Model Version 4.0.3 is used to simulate the Turbulence or CAT for the given date. The Advanced Research WRF (ARW) dynamic core in the model is used for this project as it is suitable for use in various applications across scales ranging from meters to thousands of kilometers. In this work, GrADS is used as a Post-Processing \& Visualization tool. The atmospheric reanalysis datasets can be used to identify the areas in which the onset of hydrodynamics instability in the atmospheric flow occurred and is maintained, resulting in CAT. Several indices exist to predict CAT, such as Ellrod's Index, Brown index, and Dutton index. Ellrod's Indices (TI1 and TI2 given in Eq. (6) and (8), respectively) are calculated to analyze the CAT event in this study as they are popular due to their performance, computational speed, and easy implementation. "Studies indicate that Ellrod's Indices, proposed by Ellrod and Knapp (1992), tend to perform better than others investigated" (McCann 1993; Brown et al. 2000). "The TI1 and TI2 are in operational use at aviation forecasting offices in several countries" (Ellrod and Knox 2010). "For example, TI1 is used at Dutch KNMI (Royal Netherlands Meteorological Institute)" (Overeem 2002), "TI2 is used at Swedish SMHI (Swedish Meteorological and Hydrological Institute)" (Bergman 2001), and "Met Office in U. K. has implemented the indices as well” (Turp and Gill 2008).

\subsubsection{Deformation}

CAT occurrence chance will increase when deformation in the upper-level frontal zone due to horizontal temperature gradient increases as deformation affects the horizontal temperature gradient. Deformation includes $D_{s t}$, deformation by stretching $\left(s^{-1}\right)$, i.e., downwind,

$$
D_{s t}=\frac{\partial u}{\partial x}-\frac{\partial v}{\partial y}
$$

and $D_{s h}$, deformation by horizontal shearing $\left(s^{-1}\right)$, i.e., crosswind, 


$$
D_{s h}=\frac{\partial v}{\partial x}+\frac{\partial u}{\partial y}
$$

157 The Total Deformation $\left(s^{-1}\right), D E F=\left(D_{s t}{ }^{2}+D_{s h}{ }^{2}\right)^{1 / 2}$

\subsubsection{Convergence}

The CVG, convergence term $\left(s^{-1}\right)$ included in TI2 is shown below (Eq. (4)).

$$
C V G=-\left(\frac{\partial u}{\partial x}+\frac{\partial v}{\partial y}\right)
$$

The two indices, i.e., TI1 and TI2, show fewer differences in the geographical location of the highest frequency during the summer season. This could be explained by the fact that the jet stream is weaker during summer, although the frequencies of the higher values of TI2 are significantly higher than the same for TI1. The added convergence term in TI2 can explain this. "CVG term is typically much smaller than DEF, but in some cases, it can still contribute significantly to CAT potential” (Kao and Sizoo 1966; Ellrod 1985).

\subsubsection{Vertical Wind Shear (VWS)}

The measurement of the VWS is often understood as the best indicator for the presence of CAT, as it can occur in areas with strong vertical and horizontal wind shear. "The VWS is a triggering mechanism for KHI, the primary mechanism for CAT formation" (Ellrod and Knapp 1992). The phenomenon occurs when a sufficiently large VWS within a stable layer produces breaking waves that lead to CAT. "Operational meteorologists consider Shear values of at least $6 \mathrm{kt} / 1000 \mathrm{ft}\left(\left[\frac{3 \mathrm{~ms}^{-1}}{1000 \mathrm{ft}}\right]\right.$ or $\left.9.7 \times 10^{-3} \mathrm{~s}^{-1}\right)$ as the threshold for significant (moderate or greater) CAT" (Lee et al. 1984). VWS uses results of the layer difference in u and $\mathrm{v}$ wind components from forecast data of the model as calculated in TI.

$$
V W S=\sqrt{\left(\frac{\partial u}{\partial z}\right)^{2}+\left(\frac{\partial v}{\partial z}\right)^{2}}
$$

where $\partial z$ is the thickness between the pressure levels. VWS is calculated for a layer amid two pressure levels, not a discrete pressure level. "Low-level cold advection under a ridge tends to 
increase the VWS, thereby increasing the probability of moderate to severe CAT" (Hopkins 1977). CAT is classified into various categories, as shown in Table 2.

\subsubsection{CAT Index (TI1 and TI2)}

It was discovered by Mancuso and Endlich (1966) that "VWS and deformation products gave the best correlation with CAT generation". Therefore, the turbulence index TI1 was simplified and defined by Ellrod and Knapp (1992) as Eq. (6) and (7),

$$
\text { TI1 = VWS } \times \text { DEF }
$$

From Eq. (1), (2), (3), and (5),

$$
\Rightarrow T I 1=\left(\left(\frac{\partial u}{\partial z}\right)^{2}+\left(\frac{\partial v}{\partial z}\right)^{2}\right)^{1 / 2} \times\left(\left(\frac{\partial u}{\partial x}-\frac{\partial v}{\partial y}\right)^{2}+\left(\frac{\partial v}{\partial x}+\frac{\partial u}{\partial y}\right)^{2}\right)^{1 / 2}
$$

Ellrod and Knapp (1992) also "defined a second turbulence index (TI2) which included the convergence term", as shown in Eq. (8) and (9),

$$
\mathrm{TI} 2=\mathrm{VWS} \times[\mathrm{DEF}+\mathrm{CVG}]
$$

From Eq. (1), (2), (3), (4) and (5),

$$
\Rightarrow T I 2=\left(\left(\frac{\partial u}{\partial z}\right)^{2}+\left(\frac{\partial v}{\partial z}\right)^{2}\right)^{1 / 2} \times\left[\left(\left(\frac{\partial u}{\partial x}-\frac{\partial v}{\partial y}\right)^{2}+\left(\frac{\partial v}{\partial x}+\frac{\partial u}{\partial y}\right)^{2}\right)^{1 / 2}-\left(\frac{\partial u}{\partial x}+\frac{\partial v}{\partial y}\right)\right]
$$

"TI1 is the most skillful and widely used CAT indicator in operational forecasts" (Sharman et al. 2006; Kim et al. 2011; Gill 2012). "It was found that the two indices (TI1 and TI2) give the best performance compared to other indices" (Overeem 2002). Though they do miscalculate CAT areas, the indices are still helpful. WAFC Washington uses TI1 for forecasting shear-induced turbulence, and the AFGWC in Nebraska uses TI2. "For the lower threshold, both TI1 and TI2 perform well on detecting CAT. Both indices overestimate CAT at a lower threshold but cover most turbulence reports. Based on the hits at the lower threshold, TI1 score more hits than TI2. However, based on false alarm rates, TI2 performs slightly better than TI1. For the higher threshold, the indices underestimate CAT occurrences. TI2 values are generally larger than TI1, which is probably the explanation for the higher false alarm rate." (Williams 2017). Onset thresholds for each CAT intensity category are mentioned in Table 3. Values listed in Table 3 may differ from those computed in other studies as thresholds depend on the atmospheric model's grid resolution.

\subsubsection{Bulk Richardson Number Shear (BRNSHR)}

"Bulk Richardson Number Shear (BRNSHR) is used to quantify the Vertical Wind Shear (VWS)" (Moncrieff and Green 1972), such that, 


$$
\operatorname{BRNSHR}\left(m^{2} / \mathrm{s}^{2}\right)=0.5\left(\underline{u}^{2}+\underline{v}^{2}\right)
$$

211 where $\underline{u}$ and $\underline{v}$ are "zonal and meridional wind components of the difference between the

212 density-weighted mean winds over the lowest $6000 \mathrm{~m}(\approx 500 \mathrm{hPa})$ and the lowest $500 \mathrm{~m}$

$213(\approx 950 \mathrm{hPa})$ above ground level" (Droegemeier et al. 1993). "Mesomodel output BRNSHR 214 values between $40-100 \mathrm{~m}^{2} / \mathrm{s}^{2}$ are indicative of a greater likelihood of tornadic supercell 215 thunderstorms" (Stensrud et al. 1997). The threshold value of BRNSHR for supercell 216 thunderstorms development is $40 \mathrm{~m}^{2} / \mathrm{s}^{2}$.

\section{$217 \quad 2.4$ Experimental Design}

218 This study can be classified as a climatological analysis and a regional study of a CAT event 219 in India. WRF Model V 4.0.3 is used for all simulations and configured with $6 \mathrm{~km}$ and $2 \mathrm{~km}$ 220 grid space domains. WRF model was integrated for two days, from 0000 UTC of 18 April 2212018 to 0000 UTC of 20 April 2018. The model was set to a time step of 36 seconds with 2221 hour (60 minutes) history intervals for the $1^{\text {st }}$ domain (D01) and 15 minutes history 223 intervals for the $2^{\text {nd }}$ domain (D02). The $1^{\text {st }}$ domain (D01) had $110 \times 110$ grid points, and the

$2242^{\text {nd }}$ domain (D02) had $109 \times 109$ grid points in the west-east and north-south directions. Both 225 the domains were set with 33 vertical levels. Various literature on WRF modelling and 226 simulation of CAT were studied at the beginning of this project (Wasson 2021). Thus, 227 considering results and suggestions from those works of literature, the physics 228 parameterization schemes were given weightage, and accordingly, each scheme used in this 229 study was selected. Model physics parameterization schemes used in this study to simulate 230 turbulence are given in Table 4. The most important scheme for the simulation of CAT is the 231 Planetary Boundary Layer (PBL) Scheme. When grid size is more than or equal to $1 \mathrm{~km}$, we 232 rely on PBL schemes to handle the upper air turbulence or CAT to its vertical diffusion. So, 233 different PBL schemes may give different results because they handle vertical diffusion in 234 different ways. In this study, Yonsei University Scheme is used as a PBL scheme.

\section{Results and Discussion}

236 This section discusses the results obtained from the simulations and their comparison with the 237 corresponding observations. The weather incident occurred on 19 April 2018 during 0900 238 UTC to 1200 UTC, and the model has been integrated for 48 hours, from 0000 UTC of 18 239 April 2018 to 0000 UTC of 20 April 2018. The model-designed parameters are Vertical 
240 Velocity, Horizontal Velocity, Geopotential Thickness, Vertical Wind Shear, Clear Air

241 Turbulence (CAT) Index, and Bulk Richardson Number Shear (BRNSHR).

242

243

244

245

246

247

248

249

250

251

252

253

254

255

256

257

258

259

260

261

262

263

264

265

266

267

268

269

270

\subsection{Vertical Velocity}

Vertical Velocity is an essential parameter for the occurrence of turbulence. Fig. 2 and 3 illustrate the time series of Vertical Velocity (m/s). Longitude varies from $73.4^{\circ} \mathrm{E}$ to $75.6^{\circ} \mathrm{E}$ as the turbulence was encountered for a small region. Vertical Velocity is plotted for latitude $31.3149^{\circ} \mathrm{N}$ at $450 \mathrm{hPa}$ level in Fig. 2 and different pressure levels (from $400 \mathrm{hPa}$ to $550 \mathrm{hPa}$ with intervals of $50 \mathrm{hPa}$ ) in Fig. 3 at 1000 UTC on 19 April 2018. The blue and red color region indicates downward $(-2 \mathrm{~m} / \mathrm{s})$ and upward $(6-8 \mathrm{~m} / \mathrm{s})$ velocity, respectively, at $450 \mathrm{hPa}$ level (Fig. 2 and 3(c)). So, this is a severe to extreme turbulence case (refer to Table 2). In reality, turbulence was encountered between 0900 UTC and 1000 UTC. The model simulated strong Vertical Velocity at $1000 \mathrm{UTC}$ at $74.97^{\circ} \mathrm{E}$ (Fig. 2 and 3), closer to reality.

Fig. 4 illustrates the spatial distribution of Vertical Velocity where the aircraft encountered turbulence. Plots (A) to (D) in (D01) Parent Domain (6 km) and plots (a) to (d) in (D02) Child Domain (2 km) represent Vertical Velocity at different levels (from $400 \mathrm{hPa}$ to $550 \mathrm{hPa}$ with $50 \mathrm{hPa}$ interval), respectively, at $1000 \mathrm{UTC}$ on 19 April 2018 as simulated by the model. It shows substantial and strong Vertical Velocity near the ' $\mathrm{X}$ ' mark (i.e., $74.97^{\circ} \mathrm{E}$ and $31.3149^{\circ} \mathrm{N}$ ). The negative values indicate accelerating updraft, and the positive values indicate descending downdraft. At $450 \mathrm{hPa}((\mathrm{B})$ and (b)), both upward $(6-8 \mathrm{~m} / \mathrm{s})$ and downward $(-2 \mathrm{~m} / \mathrm{s})$ velocities are seen very close to each other. From Fig. 1, it is clear that the location near ' $\mathrm{X}$ ' is where CAT was encountered. The dashed circle marks this area.

Fig. 5 illustrates the vertical profile of Vertical Velocity over the accident location with a longitude of $74.97^{\circ} \mathrm{E}$ and latitude of $31.3149^{\circ} \mathrm{N}$ at $1000 \mathrm{UTC}$ on 19 April 2018. Vertical Velocity varies with changes in pressure level (altitude). Dash patches represent the region between $400 \mathrm{hPa}$ and $550 \mathrm{hPa}$ where the model simulated strong Vertical Velocity (6$8 \mathrm{~m} / \mathrm{s}$ ). The left side of the straight line drawn on zero represents the downward velocity, and the right side represents the upward velocity. There is a sudden increase in Vertical Velocity by at least $4-5 \mathrm{~m} / \mathrm{s}$, and the speed is rising to $7 \mathrm{~m} / \mathrm{s}$ or more (from Fig. 3, 4, and 5).

\subsection{Horizontal Velocity}

Fig. 6 illustrates a comparison between the Horizontal Velocity $(\mathrm{m} / \mathrm{s})$ vertical profile over the accident location as simulated by the (a) Model at 1000 UTC, (b) ERA-Interim data at 
272 Velocity varies with changes in/pressure levels (altitude). The dash patches represent the region between $100 \mathrm{hPa}$ and $350 / \mathrm{hPa}$ where the model and other data sets simulated strong horizontal velocity $(60-65 \mathrm{~m} / \mathrm{s})$. There is a sudden increase in Horizontal Velocity by at least $40-50 \mathrm{~m} / \mathrm{s}$, and speed is rising to $62 \mathrm{~m} / \mathrm{s}$ or more. It could lead to the formation of CAT.

\subsection{Geopotential Thickness}

Fig. 7 illustrates a comparison between the Geopotential Thickness (m) on 19 April 2018 between $400 \mathrm{hPa}$ and $650 \mathrm{hPa}$, as simulated by the ((A) and (a)) Model at $1000 \mathrm{UTC}$ and ((B) and (b)) ERA-Interim data at 1200 UTC. Plots (A) and (B) represent Geopotential Thickness in (D01) Parent Domain (6 km), whereas plots (a) and (b) represent Geopotential Thickness in (D02) Child Domain (2 km). Here, ' $\mathrm{X}$ ' indicates the position where the model predicted strong Vertical Velocity near the accident location (Fig. 4). The area enclosed by the dashed circle is where the model and ERA-Interim data sets simulated a strong Geopotential Thickness (more than $36.5 \mathrm{~km}$ ). This could lead to CAT. Patches in the model simulation are not visible in ERA-Interim data simulation, as CAT is generally a microscale phenomenon. Thus, the Geopotential Thickness gradient is visible in the plot (a) of (D02) Child Domain.

\subsection{Vertical Wind Shear (VWS)}

Fig. 8 illustrates a comparison between the Vertical Wind Shear $(\mathrm{m} / \mathrm{s}$ per $1000 \mathrm{ft})$ between $200 \mathrm{hPa}$ and $850 \mathrm{hPa}$ for both the domains (D01 and D02) on 19 April 2018 as simulated by the ((A) and (a)) Model at 1000 UTC, ((B) and (b)) ERA-Interim data at $1200 \mathrm{UTC},((\mathrm{C})$ and (c)) IMDAA data at 0900 UTC and ((D) and (d)) NGFS data at 1200 UTC. Plots (A), (B), (C), and (D) represent VWS between $200 \mathrm{hPa}$ and $850 \mathrm{hPa}$ in (D01) Parent Domain (6 km), whereas plots (a), (b), (c), and (d) are representing VWS between $200 \mathrm{hPa}$ and $850 \mathrm{hPa}$ in (D02) Child Domain (2 km).

Here, ' $\mathrm{X}$ ' indicates the position where the model predicted strong vertical velocity (Fig. 4) and strong geopotential thickness gradient (Fig. 7) near the accident location. The area enclosed by the dashed circle is where the model and other data sets simulated a strong Wind Shear gradient (more than $5.5 \mathrm{~m} / \mathrm{s}$ per $1000 \mathrm{ft}$ ). So, this is a severe turbulence case (refer to Table 2). The patches in the model simulation are not visible in other data simulations as CAT is generally a microscale phenomenon that is harder to predict and requires high-resolution data sets. Thus, the Wind Shear gradient is more clearly visible in 
plot (a) of (D02) Child Domain (2 km). It could lead to CAT.

303

304

305

306

307

308

309

310

311

312

313

314

315

316

317

318

319

320

\subsection{Clear Air Turbulence (CAT) Index}

The CAT Index indicates the most probable region of CAT. Fig. 9 illustrates a comparison between CAT Index TI1 $\left(\mathrm{s}^{-2}\right)$ and CAT Index TI2 $\left(\mathrm{s}^{-2}\right)$ at different pressure levels (from $300 \mathrm{hPa}$ to $550 \mathrm{hPa}$ with $50 \mathrm{hPa}$ interval) in (D02) Child Domain (2 km) at $1000 \mathrm{UTC}$ on 19 April 2018, as simulated by the model. Plots (A) to (F) represent CAT Index TI1 $\left(\mathrm{s}^{-2}\right)$ whereas plots (a) to (f) represent CAT Index TI2 $\left(\mathrm{s}^{-2}\right)$. Here, ' $\mathrm{X}$ ' indicates the position where the model predicted strong vertical velocity (Fig. 4), strong geopotential thickness gradient (Fig. 7), and strong wind shear gradient (Fig. 8) near the accident location. The area enclosed by the dashed circle is where the model simulated strong CAT Index intensities at 1000 UTC for TI1 $\left(480.404 \times 10^{-9} \mathrm{~s}^{-2}\right)$ and TI2 $\left(503.783 \times 10^{-9} \mathrm{~s}^{-2}\right)$ at $450 \mathrm{hPa}$ level ((D) and (d), respectively). Model simulated variations in CAT Index with change in different pressure levels. The dissipation of the CAT is visible as we go higher in the atmosphere above $550 \mathrm{hPa}$. In Fig. 9, the white-colored region represents the region with No CAT intensity, the blue-colored region represents the region with Light CAT intensity, the green-colored region represents the region with Light to Moderate CAT intensity, the yellow-colored region represents the region with Moderate CAT intensity, the orangecolored region represents the region with Moderate to Severe CAT intensity, and the redcolored region represents the region with Severe CAT intensity (refer to Table 3).

Fig. 10 illustrates the comparison of Time-Series between CAT Index TI1 $\left(\mathrm{s}^{-2}\right)$ and TI2 $\left(\mathrm{s}^{-2}\right)$ for $24 \mathrm{hrs}$, i.e., from 0000 UTC on 19 April 2018 to 0000 UTC on 20 April 2018, at $450 \mathrm{hPa}$ near the accident location as simulated by the model. Here, the red-colored plot with 'o' markings represents the time-series of CAT Index TI2 $\left(\mathrm{s}^{-2}\right)$ and the blue-colored plot with ' $\mathrm{x}$ ' markings represents the time-series of CAT Index TI2 $\left(\mathrm{s}^{-2}\right)$. Model simulated variations in CAT Index with change in time. Model simulations show that CAT evolved or generated at approximately 0900 UTC near ' $X$ ' and reached the peak intensity at 1000 UTC; after that, it started dissipating at around 1200 UTC. The time-series of the CAT Index shows that at $1000 \mathrm{UTC}$, the CAT index is high, implying more chances of encountering CAT. In Fig. 10, it is visible that the model simulated strong CAT Index intensities at 1000 UTC for both TI1 $\left(480.404 \times 10^{-9} \mathrm{~s}^{-2}\right)$ and TI2 $\left(503.783 \times 10^{-9} \mathrm{~s}^{-2}\right)$ at $450 \mathrm{hPa}$ level. So, this is a severe CAT case (refer to Table 3 ) that can lead to dangerous conditions. 
It is observed that TI1 tends to overpredict, but the model simulation for TI2 is very similar to TI1. TI1 and TI2 perform similarly, but TI1 performs slightly better than TI2. Thus, (from Fig. 9, 10, and Table 3) for the lower threshold, both TI1 and TI2 perform satisfactorily for CAT detection. It is observed that both TI1 and TI2 sometimes overestimate CAT at a lower threshold, due to which they might have a high rate of false alarm; however, this might cover the maximum region of turbulence. For the higher threshold, it is observed that both TI1 and TI 2 might underestimate CAT occurrences. The TI 2 value is more than the TI1 value, explaining the high rate of false alarms.

\subsection{Bulk Richardson Number Shear (BRNSHR)}

"Bulk Richardson number shear (BRNSHR) is used to quantify the VWS" (Moncrieff and Green 1972). Fig. 11 illustrates BRNSHR $\left(\mathrm{m}^{2} / \mathrm{s}^{2}\right)$ on 19 April 2018, showing variations with time (from 0900 UTC to 1200 UTC with 1 hour time interval), as simulated by the model. Plots (A) to (D) and plots (a) to (d) represent BRNSHR variations with time in (D01) Parent Domain (6 km) and (D02) Child Domain (2 km), respectively. Here, ' $X$ ' indicates the position where the model predicted strong vertical velocity (Fig. 4), strong geopotential thickness gradient (Fig. 7), strong wind shear gradient (Fig. 8), and strong CAT Index intensity (Fig. 9) near the accident location. The area enclosed by the dashed circle is the area where the WRF model simulated strong BRNSHR $\left(235.047 \mathrm{~m}^{2} / \mathrm{s}^{2}\right)$. High values of BRNSHR $\left(235.047 \mathrm{~m}^{2} / \mathrm{s}^{2}\right)$ are simulated for the accident day around $1000 \mathrm{UTC}$ at $450 \mathrm{hPa}$ level ((B) and (b)), indicating sheared environment. So, this could show the probability of encountering turbulence that can lead to dangerous conditions.

Fig. 12 illustrates the Time-Series of BRNSHR $\left(\mathrm{m}^{2} / \mathrm{s}^{2}\right)$ for 12 hours, i.e., from 0600 UTC to 1800 UTC on 19 April 2018, near the accident location as simulated by the model. Model simulated variations in BRNSHR with change in time. The model simulations show that BRNSHR evolved or generated at approximately 0900 UTC near ' $X$ ' and reached the peak intensity at 1000 UTC; after that, it started dissipating at around 1200 UTC. The time series of BRNSHR shows that at 1000 UTC, BRNSHR is high, which implies more chances of encountering turbulence. So, this could be a severe turbulence case that can lead to dangerous conditions. Most of the BRNSHR values are more than the threshold value (40 $\mathrm{m}^{2} / \mathrm{s}^{2}$ ) for the development of supercell thunderstorms. The highest value of the BRNSHR simulated by the model is approximately $235.047 \mathrm{~m}^{2} / \mathrm{s}^{2}$ which is usually large enough to generate spinning storms. 


\section{Summary and Conclusion}

366 At high altitudes, aircraft may encounter turbulence unexpectedly without any significant cloudiness. We have already discussed how difficult is the prediction of CAT. The role of CAT for various processes in the atmosphere is still ambiguous. To know the unknown about CAT, modification of tools is essential for simulating turbulence. This study is focused on understanding and investigating favourable conditions for the occurrence of CAT. The results show that the WRF model simulated the CAT incident between Amritsar and Delhi, as reported by the Air India flight AI462 on 19 April 2018. Although limitations exist as a model cannot predict exact atmospheric conditions, it can predict close to the case; this work has proven that WRF Model V 4.0.3 used for this study is sensitive to simulate turbulence. NCEP FNL Operational Global Analysis Data at $0.25^{\circ} \times 0.25^{\circ}$ resolution with 6-hourly intervals was used as initial and boundary conditions for the model integration for 48 hours from 0000 UTC of 18 April 2018 to 0000 UTC of 20 April 2018. This study also shows that the Rapid Radiative Transfer Model (RRTM) Scheme, Yonsei University Scheme, WSM 3Class Simple Ice Scheme, Kain-Fritsch (New Eta) Scheme, and Revised MM5 MoninObukhov Scheme can be used for simulating the atmospheric conditions during a CAT event and predicting the turbulence over a region. This study shows that Vertical Velocity, Geopotential Thickness gradient, Wind Shear gradient, and BRNSHR are correlated with CAT. The TI1 and TI2 are based on deformation and might not consider additional mechanisms that might produce CAT, e.g., mountain waves. Some more studies must be done to capture the climatology of other mechanisms. The main conclusions of this study are:

- This is a severe CAT case, and the results show that the WRF model reasonably predicts turbulence. The most important scheme for the simulation of CAT is the PBL Scheme. In this study, Yonsei University Scheme is used as a PBL scheme.

- Model simulated both upward (6-8 m/s) and downward $(-2 \mathrm{~m} / \mathrm{s})$ velocity, very close to each other between $400 \mathrm{hPa}$ and $550 \mathrm{hPa}$ levels at $1000 \mathrm{UTC}$ near the accident location. So, this is a severe to extreme turbulence case (refer to Table 2).

- Model and other data sets simulated strong horizontal velocity (60-65 m/s) at the same region between $100 \mathrm{hPa}$ and $350 \mathrm{hPa}$ levels near the accident location.

- Model and other data set simulated strong Geopotential Thickness (more than $36.5 \mathrm{~km}$ ) and strong Wind Shear gradient (more than $5.5 \mathrm{~m} / \mathrm{s}$ per $1000 \mathrm{ft}$ ) near the ' $\mathrm{X}$ ' location at 1000 UTC. So, this is a severe turbulence case (refer to Table 2). 
- Model simulated variations in CAT Index with change in time and pressure levels. CAT dissipates as we go higher in the atmosphere above $550 \mathrm{hPa}$.

- Model simulations show that CAT evolved or generated at approximately 0900 UTC near ' $\mathrm{X}$ ' location and reached the peak intensity at $1000 \mathrm{UTC}$; after that, it started dissipating at around 1200 UTC.

- The model simulated strong CAT Index intensities for TI1 $\left(480.404 \times 10^{-9} \mathrm{~s}^{-2}\right)$ and TI2 $\left(503.783 \times 10^{-9} \mathrm{~s}^{-2}\right)$ at $450 \mathrm{hPa}$ level at $1000 \mathrm{UTC}$ (from Fig. 9, 10, and Table 3), at the exact location where the model predicted strong vertical velocity (Fig. 4), strong geopotential thickness gradient (Fig. 7), and strong wind shear gradient (Fig. 8) near ' $X$ ' location, closer to reality. So, this is a severe CAT case (refer to Table 3 ) that can lead to dangerous conditions.

- TI1 and TI2 perform similarly, but TI1 performs slightly better than TI2.

- The model also simulated variations in BRNSHR with changes in time. Model simulations show that BRNSHR evolved or generated at approximately 0900 UTC near ' $\mathrm{X}$ ' and reached the peak intensity at $1000 \mathrm{UTC}$; after that, it started dissipating at around 1200 UTC. High values of BRNSHR $\left(235.047 \mathrm{~m}^{2} / \mathrm{s}^{2}\right)$ are simulated at around 1000 UTC for the accident day at $450 \mathrm{hPa}$ level (Fig. 11 and 12), indicating sheared environment. Thus, this could show the probability of encountering turbulence as the high intensity of BRNSHR indicates more chances of encountering turbulence.

Even though there are differences in reality and model prediction, the model can still predict turbulence. We should also know how significantly other schemes can predict turbulence by finding different parameterization scheme combinations to predict turbulence more accurately. Only one case is discussed in this study, but many other cases are being reported worldwide, and only after studying a more significant number of cases can we tell the exact behaviour of CAT. These all will do in the future as a continuation of this work.

\section{Statements and Declarations}

Acknowledgements: Authors gratefully acknowledge NCMRWF, Ministry of Earth Sciences, Government of India for IMDAA reanalysis. IMDAA reanalysis was produced under the UK Met Office, NCMRWF, and IMD with financial support from the Ministry of Earth Sciences under the National Monsoon Mission programme. Authors gratefully acknowledge NCMRWF, Ministry of Earth Sciences, Government of India, for NGFS 
reanalysis, produced under the collaboration between NCMRWF, IITM, and IMD. The constructive comments of the reviewers are gratefully acknowledged.

430 Funding: The authors declare that no funds, grants, or other support were received during the preparation of this manuscript.

432 Competing Interests: The authors have no relevant financial or non-financial interests to 433 disclose.

Author Contributions: All authors contributed to the study's conception and design. Material preparation, data collection, and analysis were performed by Gitesh Wasson. The first draft of the manuscript was written by Gitesh Wasson, and all authors commented on previous versions of the manuscript. All authors read and approved the final manuscript.

\section{References}

Bergman S (2001) Verification of the Turbulence Index used at SMHI. Examensarbete vid Institutionen för geovetenskaper ISSN 1650-6553 Nr 2, Uppsala University

Brown BG., Mahoney JL, Henderson J, Kane TL, Bullock R, Hart JE (2000) The turbulence algorithm intercomparison exercise: Statistical verification results. Preprints. Ninth Conference on Aviation, Range and Aerospace Meteorology, Orlando

DGCA Report (2019) FINAL INVESTIGATION REPORT INCIDENT TO M/s AIR INDIA BOEING 787-800 AIRCRAFT VT-ANI ON 19/04/2018 IN AMRITSAR AIRSPACE. Civil Aviation Department Report, Government of India

Droegemeier KK, Lazarus SM, Davies-Jones R (1993) The Influence of Helicity on Numerically Simulated Convective Storms. Monthly Weather Rev 121(7):2005-2029. https://doi.org/10.1175/1520-0493(1993)121\%3C2005:TIOHON\%3E2.0.CO;2

Dutton AJ, Panofsky HA (1970) Clear Air Turbulence: A Mystery May Be Unfolding. The American Association of Physics Teachers, Science 167(3920):937-944. https://doi.org/10.1126/science.167.3920.937

Ellrod GP (1985) Detection of high-level turbulence using satellite imagery and upper air data. NOAA Technical Memorandum NESDIS 10, U. S. Department of Commerce, Washington. 
Ellrod GP, Lester F, Ehernberger LJ (2003) Clear air turbulence. Encyclopedia of Atmospheric Science 1:393-403, edited by JR Holton et al., Academic Press, New York. http://dx.doi.org/10.1016/B0-12-227090-8/00104-4

Ellrod GP, Knapp DI (1992) An Objective Clear-Air Turbulence Forecasting Technique: Verification and Operational Use. Weather and Forecasting 7(1):150-165. http://dx.doi.org/10.1175/1520-0434(1992)007\%3C0150:AOCATF\%3E2.0.CO;2

Ellrod GP, Knox JA (2010) Improvements to an Operational Clear-Air Turbulence Diagnostic Index by Addition of a Divergence Trend Term. Weather and Forecasting 25(2):789-798. https://doi.org/10.1175/2009WAF2222290.1

Ellrod GP, Knox JA, Lester PF, Ehernberger LJ (2015) Aviation: Clear Air Turbulence. Encyclopedia of Atmospheric Science 2(1):177-186. https://doi.org/10.1016/ B978-0-12-382225-3.00104-3

ECMWF (2011) The ERA-Interim reanalysis dataset, Copernicus Climate Change Service (C3S). https://www.ecmwf.int/en/forecasts/datasets/archive-datasets/reanalysisdatasets/era-interim. Accessed 17 March 2021.

Gill PG (2012) Objective verification of World Area Forecast Centre clear air turbulence forecasts. Meteorological Applications 21(1):3-11. https://doi.org/10.1002/met.1288

Gill PG, Buchanan P (2013) An ensemble-based turbulence forecasting system. Meteorological Applications 21(1):12-19. https://doi.org/10.1002/met.1373

Hopkins RH (1977) Forecasting techniques of clear air turbulence including that associated with mountain waves. WMO Technical Note No. 155.

ICAO (2005) Manual on Low-level Wind Shear. First Edition, International Civil Aviation Organization. https://www.skybrary.aero/bookshelf/books/2194.pdf

Kao SK, Sizoo AH (1966) Analysis of clear air turbulence near the jet stream. J Geophysical Res 71(16):3799-3805. https://doi.org/10.1029/JZ071i016p03799

Kim J-H, Chun H-Y (2011): Statistics and Possible Sources of Aviation Turbulence over South Korea. J Appl Meteorology and Climatology 50(2):311-324. https://doi.org/10.1175/2010JAMC2492.1

Lee DR, Stull RS, Irvine WS (1984) Clear Air Turbulence Forecasting Techniques. Air Weather Service (MAC), Air Force Global Weather Central, Technical Note AFGWC/TN-79/001 (REV). https://apps.dtic.mil/sti/pdfs/ADA083099.pdf

Lester PF (1993) Turbulence: A New Perspective for Pilots. Jeppesen Sanderson: Englewood, CO, USA. 
Mazon J, Rojas JI, Lozano M, Pino D, Prats X, Miglietta MM (2018) Influence of meteorological phenomena on worldwide aircraft accidents, 1967-2010. Meteorological Applications 25(2):236-245. https://doi.org/10.1002/met.1686

Mancuso RL, Endlich RM (1966) Clear Air Turbulence Frequency as a Function of Wind Shear and Deformation. Monthly Weather Rev 94(9):581-585. https://doi.org/10.1175/1520-0493(1966)094\%3C0581:CATFAA\%3E2.3.CO;2

McCann DW (1993) An evaluation of clear-air turbulence indices. Preprints, Fifth International Conference on Aviation Weather Systems, 1-6 August 1993, Vienna, Virginia.

Moncrieff MW, Green JSA (1972) The propagation and transfer properties of steady convective overturning in shear. Q J R Meteorological Society 98(416):336-352

NCEP/NWS/NOAA/U.S. Department of Commerce (2015): NCEP GDAS/FNL 0.25 Degree Global Tropospheric Analyses and Forecast Grids. Research Data Archive at the National Center for Atmospheric Research, Computational and Information Systems Laboratory, Boulder, CO. https://doi.org/10.5065/D65Q4T4Z. Accessed 23 March 2021

Overeem A (2002) Verification of clear-air turbulence forecasts. Techisch rapport, KNMI

Passner JE, Knapp DI (2008) Using WRF-ARW Data to Forecast Turbulence at Small Scales. $13^{\text {th }}$ Conference on Aviation, Range and Aerospace Meteorology Battlefield Environment Division, U. S. Army Research Laboratory, White Sands Missile Range, New Mexico. https://ams.confex.com/ams/pdfpapers/128617.pdf

Prasad VS, Johny CJ, Mali P, Singh SK, Rajagopal EN (2016) Retrospective Analysis of NGFS for the years 2000-2011. Curr Science 112(2):370-377. Accessed 9 April 2021

Rani SI, Arulalan T, George JP, Rajagopal EN, Renshaw R, Maycock A, Barker D, Rajeevan M (2021) IMDAA: High Resolution Satellite-era Reanalysis for the Indian Monsoon Region. J Climate. https://doi.org/10.1175/JCLI-D-20-0412.1. Accessed 13 April 2021

Reiter ER (1963) Jet-stream Meteorology. Q J R Meteorological Society 90(385):366-367, University of Chicago Press. https://doi.org/10.1002/qj.49709038525

Sharman R, Tebaldi C, Wiener G, Wolff J (2006) An integrated approach to mid- and upperlevel turbulence forecasting. Weather and Forecasting 21:268-287. https://doi.org/10.1175/WAF924.1

Spensberger C, Spengler T (2014) A New Look at Deformation as a Diagnostic for LargeScale Flow. J Atmospheric Science 71(11):4221-4234. https://doi.org/10.1175/JASD-14-0108.1

Stefan S, Antonescu B, Urlea AD, Buzdugan L, Andrei MD, Necula C, Voinea S (2020) 
Study of Clear Air Turbulence Related to Tropopause Folding over the Romanian Airspace. Atmosphere 11(10). https://doi.org/10.3390/atmos11101099

Steffenel LA, Charão AS, Alves B, de Araujo LR, da Silva LF (2020) MPI to Go: Container Clusters for MPI Applications. Cloud Computing and Services Science, CLOSER 2019, Communications in Computer and Information Science, Springer 1218:199222. https://doi.org/10.1007/978-3-030-49432-2_10

Stensrud DJ, Cortinas Jr. JV, Brooks HE (1997) Discriminating between Tornadic and Nontornadic Thunderstorms Using Mesoscale Model Output, Weather and Forecasting 12(3):613-632. https://doi.org/10.1175/1520-0434(1997)012\%3C0613: DBTANT\%3E2.0.CO;2

Turp D, Gill P (2008) Developments in Numerical Clear Air Turbulence Forecasting at the U. K. Met Office. Preprints, $13^{\text {th }}$ Conference on Aviation, Range and Aerospace Meteorology, New Orleans, LA, American Meteorological Society P3.10A

Venkatesh TN, Mathew J, Nanjudiah RS (2014) Secondary instability as a possible mechanism for Clear Air Turbulence: a case study, Meteorology and Atmospheric Phys 126:139-160. https://doi.org/10.1007/s00703-014-0344-2

Wasson G (2021): Numerical Simulation of Clear Air Turbulence (CAT) for alleviation of aviation accidents using Weather Research and Forecasting (WRF) model. Dissertation, Department of Atmospheric Science, Central University of Rajasthan

Williams PD, Joshi MM (2013) Intensification of winter transatlantic aviation turbulence in response to climate change. Nat Climate Change 3:644-648. https://doi.org/10.1038/nclimate1866

Williams PD (2017) Increased light, moderate, and severe clear-air turbulence in response to climate change. Advances in Atmospheric Sciences 34:576-586. https://doi.org/10.1007/s00376-017-6268-2 